\title{
NArchitecTURE: A Paradigm of Design with Nature
}

\author{
Xiaohong Ling ${ }^{1 *}$ \\ ${ }^{1}$ School of Architecture, South China University of Technology, 510641 Guangzhou, China
}

\begin{abstract}
The relationship between architecture and nature has been a constant debate in the field. The preposition that architecture is an integral part of nature and even the natural landscape itself has accompanied the development of architectural theories over time. However, the question of how nature can be a design language intrinsically involved in the design process has not been systematically explored. This paper, therefore, through initiating the concept of NArchitecTURE, commences with a review of relevant theories concerning the relationship between nature and architecture. And then, through investigating a number of pioneering design works, this paper identifies a series of morphological types and spatial patterns that NArchitecTURE can produce. By means of proposing an alternative design paradigm by working with nature, this paper aims to provide contemporary architects with valuable inspiration to achieve environmental sustainability.
\end{abstract}

\section{Introduction}

Since the emergence of architecture, its relationship with nature has been a constant debate in society. 'Man is that unique conscious creature who can perceive and express. He must become the standard of the biosphere. To do this, he must design with nature, ${ }^{[1]}$. McHarg has pointed out that the inherent characteristics of humans determine their creative activities necessarily back to nature. Nowadays, while architecture is no longer deemed a selforientated entity without paying attention to its surrounding environment, there is a need for us to explore how nature can be, as a design language, effectively involved in the design process. It is worth noting that this kind of integration can produce countless design possibilities in light of interdisciplinary initiatives.

Over the past century, there have emerged a large number of innovative design ideas emphasizing our relationship with nature. However, little of the literature expounds these notions systematically. Therefore, this paper is an attempt to define a concept of NArchitecTURE, reviewing its formation and development at the theoretical level, subsequently identifying a series of relational schema in order to provide contemporary architects with valuable guidance and inspiration.

\section{Theoretical Foundation of NArchitecT- URE}

NArchitecTURE defined in this paper can be regarded as landscaped architecture or architecturalized landscape. However, it is not equivalent to the scope and content that contemporary landscape architecture covers. In fact, the concept of NArchitecTURE did not emerge merely in the contemporary era, it is fair for us to find that architecture theories have constantly contained such themes and ideas, demonstrating that humans have never stopped thinking about their relationship to nature. Also, in such a process, they have mingled with complicated emotions, including fear, surrender, praise and interaction.

Figure-ground was an earlier principle used to explore the relationship between architectural spaces and external environment. As derived from Gestalt theory, visual perception can be divided into two parts - a figure (the object of attention) and a ground. Phenomenologically, these two sub-fields are different, each one having its own characteristics and playing different roles in humans' visual perception. The best illustration of the principle in history was the Map of Rome drawn by Nolli in 1748 (Fig.1). Through revealing the city as a clearly defined system of solids and voids, the map illustrated that buildings created voids, and the voids seemed to be carved out of buildings, linking exterior and interior spaces and activities. As a result, the outdoor spaces appeared as positive, and were more figural than the solids that define them.

With the development of modernist ideology in the late nineteenth century, architectural design began to emphasize functionalism and technical rationality. As a result, urban development was inclined to treat buildings as isolated objects situating within natural landscape rather than being an integral part of the spatial system comprising streets, squares and other open spaces ${ }^{[2]}$. Within this kind of urban environment, buildings looked like monuments, with spaces between them being vast and formless and lacking a coherent connection. Also, it was easy to find that the compact and coherent figureground relationship as shown in traditional towns did not exist any longer.

\footnotetext{
* Corresponding author: arlingxh@scut.edu.cn.
} 
In the mid-twentieth century, modernist ideology and mechanical determinism were gradually deemed controversial. One of the most influential opponents was Team X, who contended that it was precisely the principle that advocated zoning and isolated high-density built environment leading to the lack of coherent links and the loss of urban vitality. In practice, they abandoned the functional idealism promoted by CIAM. Based on the analysis of the complexity and growth pattern of traditional urban structures, they proposed a series of spatial patterns to highlight the structural continuity and flexibility, which was ultimately defined as mat architecture. Mat architecture, as a symbol of modernist architecture toward a new direction, no longer stood out against surrounding environment, but functioned as an integrated part of it.

Since the 1960s, the development of architecture has entered its post-modern era. Postmodernism was an era to promote individualism. To facilitate the complexity and diversity of the real world, architecture discipline exhibited the coexistence of different styles. In light of the reflection on the modernism, the relationship between nature and built environment once again aroused intense public debates, leading to the emergence of a number of theories and doctrines that have significantly influenced contemporary design exercises. Among them, 'A city is not a tree' advocated by Christopher Alexander criticized the tree diagram that governed the planning of the time ${ }^{[3]}$. In opposition to this deterministic diagram at the base of artificial cities, Alexander proposes that a city settles over time and is structured as a 'semi-lattice' (Fig. 2), an open structure where the parts are connected to each other by several orders of relationship, and the elements of a smaller scale may interact with others without being subjected to an inflexible hierarchy. In 1985, another theorist Stan Allen, with reference to the unique characteristics of Mat architecture in modernism, put forward field theory ${ }^{[4]}$. Field theory further blurs the boundaries between architecture and natural landscape, describing a spatial phenomenon or state of existence resulting from the interaction of humans, materials and information flows (Fig. 3). Field theory is deemed a turning point for the development of Western architecture, because it extends the boundaries of architecture, making another possibility in the real world. Field conditions can be any forms of spaces following a certain logic and integrating various elements. The Intrinsic connection and internal porosity determine the fuzzy boundaries and loose characters of fields, enabling them to possess liquid-like forms and high degree of adaptability ${ }^{[4]}$.

Similarly, contemporary theorist Charles Jencks ${ }^{[5]}$, summed up the impact of complexity science on the development of contemporary architecture. He stated that unlike modernist simplicity based on a deterministic mechanism, the core of postmodern architecture features chaos and complexity science. On this basis, he further summarized eight main features of post-modern architecture. For example, architecture should be close to nature and natural language, which is a holistic manner of tying people to nature, and so on. By contrast, fractal theory from another angle, laid the theoretical foundation for the realization of NArchitecTURE. As its name suggests, fractal theory is a science to describe the regularity rules underlying irregular things of nature. According to Mandelbrot ${ }^{[6]}$, a fractal is a rough or fragmented geometric shape that can be subdivided into parts, each of which is a reduced-size copy of the whole. Therefore, fractal theory is a new methodology and perspective, from which the most common state of the real world and the way the world evolves are able to be described and understood.

From above, it is found that the relationship between architecture, landscape and nature is an important topic accompanied with the development of architecture. From the original living prototype in ancient times to the modernist doctrine of isolation and mechanization, and to the complexity science and chaos occurred in the late twentieth century, they all try to achieve the integration with nature. In this case, NArchitecTURE, being considered as a conceptual framework to establish the relationship of architecture with the context, obtains its foundation from these theories. Furthermore, the magnificence of science and technology, as well as the interdisciplinary tendency among landscape, architecture, and urban planning, have enabled NArchitecTURE to be developed into a design paradigm, playing an important role in contemporary design exercise.

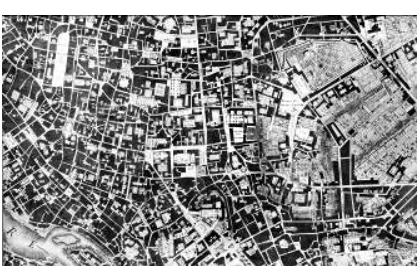

Fig. 1. Nolli. Map of Rome

1748. (Source: Earth Sciences \& Map Library-University of California, Berkeley)

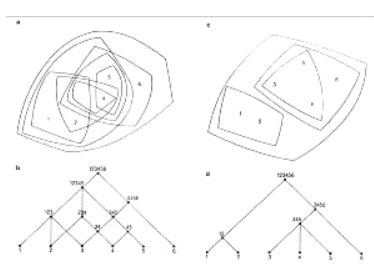

Fig. 2. A city is not a tree. (Source:www.europaneurop e.eu/media/default/)
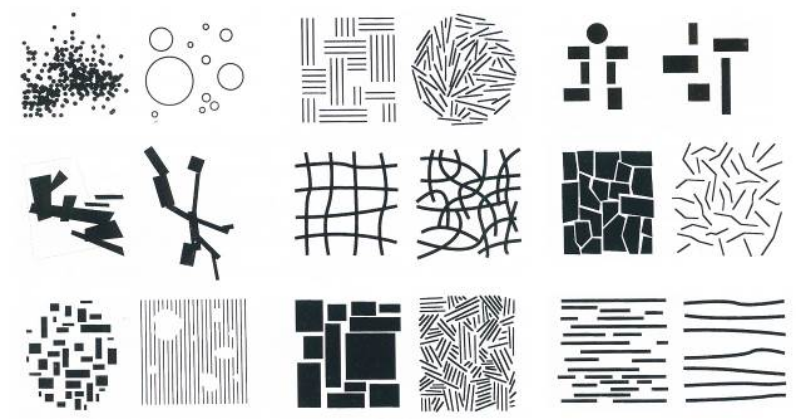

Fig. 3. Stan Allen's field conditions. (Source: Points + Lines: Diagrams and Projects for the City. Princeton Architectural Press: New York, 1999)

\section{Morphological types of NArchitecT- URE}

\subsection{Metaphor and symbolism of nature}

The most obvious manifestation of NArchitecTURE is the building that takes its imagery from the natural geological features. For example, some buildings are 
actually idealized mountains, rocks, and water. At this time, architecture is considered as a metaphor or symbolism where the natural phenomena are transformed into a particular design language. By means of abstraction and optimization, architecture establishes its inherent connection with nature.

\subsection{Merging with nature}

Another prominent manifestation of NArchitecTURE is to fit buildings into slopes as mountain architecture does. Normally, mountain architecture refers to the building located along a steep slope and whose layout is carefully configured by taking into account the specific geomorphologic features. The Rokko Collective Housing designed by Tadao Ando in Japan is well-known for its successful dealing with slopes (Fig. 4).

The earth-sheltered structure is another morphological model of NArchitecTURE. Different from mountain architecture, earth-sheltered structures merge with nature in a straightforward way. An earthsheltered structure refers to buildings placed completely or partially underground, but not just simply buried. Rather, they comprise a great deal of wisdom, embodying a number of adaptive design strategies. In addition to preserving natural landscape and reducing interference with the environment, it enables architecture to establish an intimate relationship with the landscape. There is no surprise that earth-sheltered architecture can be found worldwide. One of the outstanding representative architects is Emilio Ambasz, whose early works mainly featured underground forms (Fig. 5).

\subsection{Ambiguous figure-ground relationship}

As mentioned, the figure-ground principle is used to describe the shape and proportional relationship between buildings and external spaces. Nowadays, it has been considered as a way of thinking to achieve NArchitecTURE. Through blurring the figure-ground boundaries, architecture obtains a new meaning in its surroundings, and obtaining obscurity between internal and external spaces. In comparison with other models of melting with nature, ambiguous figure-ground tends to achieve structural and inherent integration between different elements. Through breaking the boundaries between inside and outside, architecture no longer stands alone, but as a field condition merging with surrounding landscape. The Museum of Islamic Art proposed by Zaha Hadid can be viewed as a good example to embody the concept within a unique urban environment. Through establishing a three-dimensional interface between the architecture and nature, the sense of NArchitecTURE is formulated.

\subsection{Folding and bifurcation}

Traditional theories often overlooked the idea of events occurring in architecture, as well as ignoring the influence of dynamic spaces on the pattern of human behaviour. To break the tradition, many contemporary architects, such as Peter Eisenman and Grey Lynn, have worked with the concept of folding in their design exercises. Through creating continuous interfaces and multi-level connections among different elements, they have produced a series of seamless spaces and forms (Fig. 6). According to Grey Lynn's definition, folding means assimilating independent or unrelated matters into a constant mixture. In light of the ideas, there are no boundaries between the vertical and the horizontal, between the figure and the ground, breaking up the existing Cartesian order of spaces. Likewise, Eisenmen stresses 'weak forms' in his practice, implying that architecture should embody an organic form in order to harmonize with its natural environment ${ }^{[7]}$. One of the most famous examples of folding architecture of the world is the Yokohama International Terminal designed by FOA (Foreign Office Architect).

\subsection{Landform architecture}

In a broader sense, the meaning of landform architecture has some overlapping with that of NArchitecTURE. That is, both of them present the concept of nature, and express the natural characteristics of architecture by means of particular spatial patterns and forms. However, landform architecture more specifically refers to the structure that possess a high degree of integration with the natural terrain, such as topography, land texture, and so on. In most circumstances, its spatial form derives from a combination of metaphor, symbolism, melting, and even folding tactics ${ }^{[8]}$. For example, Charles Jencks' Universe Cascade can be considered as an early landform design for the sake of creating a strong symbolic landscape (Fig. 7).

\subsection{Generative design}

In comparison with other NArchitecTURE types, generative design features a high level of innovation and a certain subversive-ness in both thinking and techniques. By taking advantage of computer technologies, it generates images, sounds, models, and animation based on a set of rules or an algorithm. Through parametric modelling, generative design has been regarded as an effective tool to explore a variety of design possibilities rapidly. With reference to the inherent law or the process of natural lives, this method can simulate biological behavioral patterns at different scales, from an organism, organ, a cell, or molecular structure, creating a new design language or a new spatial environment. Benefiting from the rapid development of digital technology, generative design has increasingly turned into an independent discipline, gaining its ground in architectural education and in practice. 


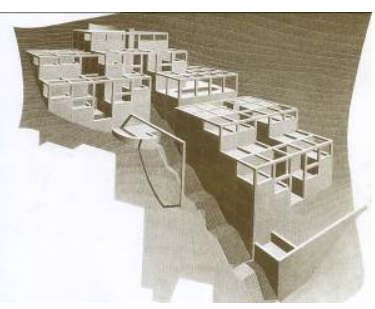

Fig. 4. Ando's Rokko

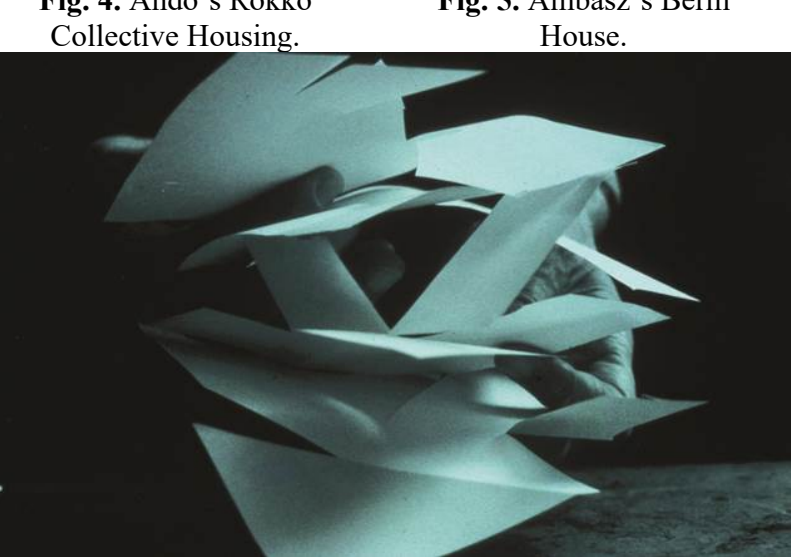

Fig. 6. Folding architecture.

(Source://oma.eu/projects/jussieu-two-libraries)

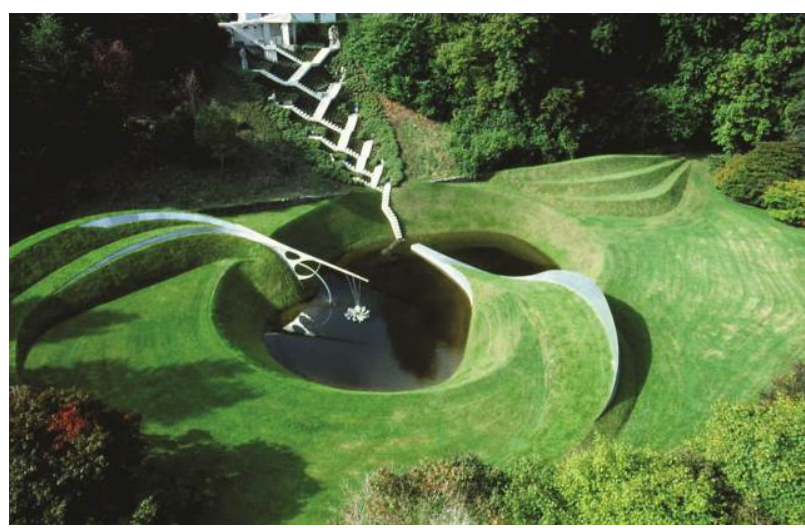

Fig. 7. Charles Jencks' Universe Cascade. (Source: //assets.inhabitat.com/wp-content/blogs.dir/)

\subsection{Epilogue}

Form above, it is worth noting that the development of contemporary architecture has increasingly displayed a multi-variate pattern, with a large number of design exercises based on the combination of various conceptual models. Attributed to the advancement of both science and technology, people are more likely to explore the nature thoroughly than before. In turn, the richness and diversity of nature are bound to provide an endless source for human's creativity. In this sense, NArchitecTURE will inevitably be further developed and evolved, with more and more morphological possibilities emerging in future.

\section{Spatial patterns of NArchitecTURE}

This section aims to demonstrate how the concept of NArchitecTURE can be transformed into specific design strategies, subsequently producing unique type of spaces.

\subsection{Liquid space}

Based on the concept of metaphor or folding, one possible spatial pattern is liquid space, which is based on non-linear thinking to solve particular design problems. The rationale behind is that architecture can be liquidlike so as to create a seamless relationship between architecture and nature, between different parts of the building (Fig. 8). More than that, it can generate dynamic behavioural patterns inside the space.

\subsection{Spatial homogeneity}

Spatial homogeneity, as another spatial pattern of NArchitecTURE, tends to solve various design problems from the perspective of interdisciplinary thinking, such as from biology and physics. In a general sense, homogeneity is defined as the quality or state of being homogeneous (of the same or similar nature). It also means having a uniform structure throughout. In physics, homogeneity usually means describing a system that has the same properties at every point of space; it also describes a substance or an object whose properties do not vary with its position. With reference to the concept of spatial homogeneity, architecture appears as a biosystem with uniform elements articulated by an inherent logic or as a system with different elements, but with a uniform composition (Fig. 9).

In this spatial pattern, systematic thinking is considered to be essential in terms of various hierarchies and scales. Other than conventional design methods beginning from programs and forms, systematic design opens up a much wider range of methodologies embedded with thoughtful collaboration between architects and other disciplines. In this sense, NArchitecTURE is no longer merely an addition to certain boxes that architects have already made, but it truly becomes a powerful and meaningful agenda to figure out internal logics or connections behind spatial phenomena.

\subsection{Eco-society}

Eco-society is a design approach based on the concept that NArchitecTURE can help solve particular social problems. This design principle mainly discusses how nature can be an opportunity or a catalyst to promote social fairness, equality and harmony, helping achieve social sustainability. Owing to the inherent characteristics of human beings, through providing opportunities to interact with nature, human minds are able to be purified and their spirit and value are also transformed. Though establishing the interaction between architecture and nature, Eco-society can help rebuild people's relationship and establish an ideal social structure.

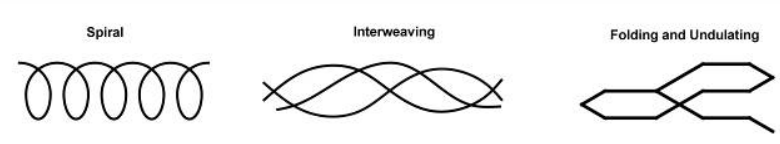

Fig. 8. Types of liquid spaces. 


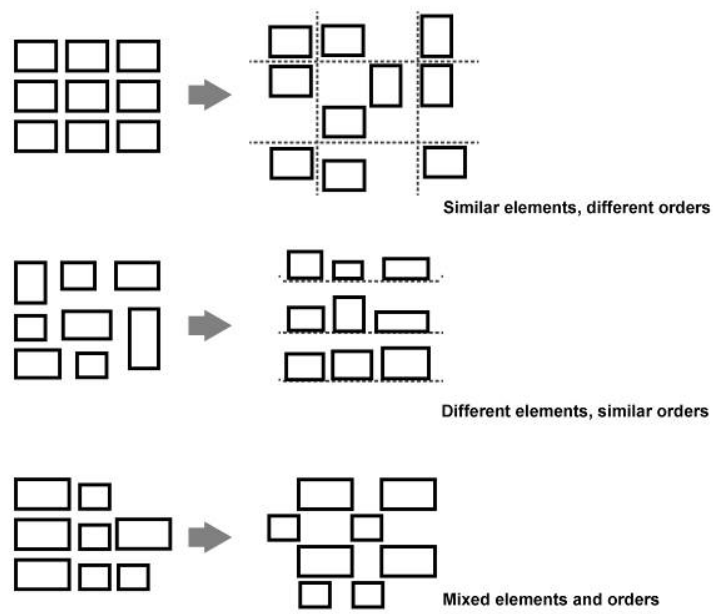

Fig. 9. Spatial homogeneity

\section{Conclusion}

There is no doubt that architectural design is facing constant challenges; but meanwhile, is inspired by the development of technology and science, both architectural theories and practice have numerous opportunities to be advanced. This paper has shown that as a design paradigm, NArchitecTURE can produce various design possibilities by working with nature. Owing to the richness and complexity of the nature, it is believed that the potential of NArchitecTURE can be further explored, opening up a new dimension for architects to promote the interaction between humans and nature and subsequently leading to environmental sustainability.

\section{Acknowledgements}

This research was financially supported by State Key Laboratory of Subtropical Building Science Research, SCUT (2020ZB08), Guangzhou Philosophy and Social Science Planning Project (2020GZGJ16), and Guangdong Philosophy and Social Science Planning Post-funded Project (GD20HTQ01).

\section{References}

1. McHarg, Ian L. (1969) Design with Nature. Natural History Press: New York.

2. Trancik, R. (1986) Finding Lost Space: Theories of Urban Design. Van Nostrand Reinhold: New York

3. Alexander, C. (1965) A City is Not a Tree. Architectural Forum, 122(1), pp: 58-62.

4. Allen, S. (1999) Points + Lines: Diagrams and Projects for the City. Princeton Architectural Press: New York.

5. Jencks, C. (1997) The Architecture of the Jumping Universe-- a Polemic: How Complexity Science is Changing Architecture and Culture. Academy Editions: London.
6. Mandelbrot, B. B. (1982) The Fractal Geometry of Nature. Freeman: San Francisco.

7. Eisenman, P. (1999) Diagrams of Anteriority. Diagram Dairies, Universe.

8. Allen, S. and McQuade, M. (edit.). (2011) Landform Building: Architecture's New Terrain. Lars Müller Publishers: Baden, Switzerland; Princeton University School of Architecture: Princeton. 